Article

\title{
Gene Introgression among Closely Related Species in Sympatric Populations: A Case Study of Three Walnut (Juglans) Species
}

\author{
Meng Dang ${ }^{1}$, Ming Yue ${ }^{1,2}$, Min Zhang ${ }^{1}$, Guifang Zhao ${ }^{1}$ and Peng Zhao ${ }^{1, * \mathbb{D}}$ \\ 1 Key Laboratory of Resource Biology and Biotechnology in Western China, Ministry of Education, \\ College of Life Sciences, Northwest University, Xi'an 710069, China; 15339260798@163.com (M.D.); \\ yueming@nwu.edu.cn (M.Y.); minzhang@stumail.nwu.edu.cn (M.Z.); gfzhao@nwu.edu.cn (G.Z.) \\ 2 Xi'an Botanical Garden of Shaanxi Province, Xi'an 710061, China \\ * Correspondence: pengzhao@nwu.edu.cn; Tel./Fax: +86-29-88302411
}

Received: 25 September 2019; Accepted: 30 October 2019; Published: 1 November 2019

\begin{abstract}
Gene introgression usually results from natural hybridization occurring among closely related species in sympatric populations. In this study, we discussed two rare and frequent gene flow phenomena between three species of Juglans plants and analyzed the possible causes for the difference. We collected 656 individuals from 40 populations of Persian walnut (Juglans regia L.), Chinese walnut (J. cathayensis Dode), and Iron walnut (J. sigillata Dode) that were genotyped at 17 expressed sequence tag simple sequence repeat (EST-SSR) loci to analyze the introgressions between $J$. regia and J. cathayensis, and J. regia and J. sigillata. Our study compared the spatial patterns of expected heterozygosity $\left(H_{E}\right)$, allelic richness $(R s)$, and private allele richness $\left(P_{A R}\right)$ so as to vividly infer the biogeographic history of related species of Juglans in the two regions. The results of the PCoA, UPGMA, and STRUCTURE analyses showed that all J. regia and J. sigillata populations clustered into one group, and the J. cathayensis populations clustered into the other group. The results of the historical gene flow analysis indicated that J. regia and J. sigillata have no genetic barriers, and the directional gene flow is mainly from J. regia to J. sigillata. For the three species of Juglans, all the above results indicated that gene flow was common among the same group of Juglans, and only rare and low-level gene flow appeared in distinct groups. Therefore, our study revealed multiple phenomena of gene flow and introgression among closely related species in sympatric populations, thereby providing a theoretical basis for the genetic evolution of the genus Juglans.
\end{abstract}

Keywords: gene introgression; microsatellites; genetic diversity; sympatric populations; Juglans

\section{Introduction}

Interspecies introgression can cause base substitution and deletion of DNA fragments, leading to a decrease in species specificity, which is likely to promote adaptive evolution of the infiltrated species [1-3]. Interspecific hybridization occurs frequently in sympatric forest trees. Morphology may provide some useful information to identify hybrids, but molecular markers are more reliable at identifying hybrids. Nuclear DNA sequences can be used to differentiate among closely related lineages, to clarify cases of sympatric speciation, and to identify hybrid individuals [4-7]. Studies have shown that hybridization and gene flow between species occur extensively in the genus Populus [8-12]. One of these studies showed that Populus $\times$ jrtyschensis is typical of F1 dominated hybrid zones between the distantly related species, P. nigra and P. laurifolia [12]. In the genus Eriobotrya Lindl., compelling evidence indicated that most haplotypes of E. prinoides var. Daduheensis were also shared with those of E. japonica and E. prinoides to produce a hybrid status for E. prinoides var. Daduheensis [13]. However, 
most of these studies only focused on investigating the frequent gene flow between two closely or distantly related species and rarely reported on a variety of gene flow among a single genus.

Walnuts (Juglans), one of the eight living genera in the family Juglandaceae, have about 21 species in the world, with a distribution from tropical to temperate zones, and from Asia to Europe and the Americas [14-19]. The walnut (Juglans) has always been the focus of biological research because of its economic, culinary, and medicinal value. Although more and more scholars have revealed the genetic diversity and genetic structure of walnut populations, few studies have been done on the interspecific hybridization and gene flow between walnuts. Hybridization between species of the genus Juglans is common because of the weak reproductive isolation mechanisms between phylogenetically close species [20-24]. This study is the first to explore the interspecific hybridization of Chinese Juglans plants and provides a theoretical basis for the genetic evolution of the genus Juglans.

Previous studies on the morphology, molecular biology, phenological, and fossils indicated that Juglans plants are classified into two sections that are distributed in China, section Juglans and section Cardiocaryon [15,25-27]. Section Juglans includes the two cultivated walnuts, J. regia and J. sigillata. Section Cardiocaryon contains three taxa, J. manshurica M., J. cathayensis, and J. hopeiensis $\mathrm{Hu}$. These five species are different from each other in numerous ways, from leaves to branches and flowers [17,25-30]. In order to further investigate the gene introgression between Juglans species, we selected the aforementioned two groups (section Juglans and section Cardiocaryon) of walnut species to study (J. regia, J. sigillata, and J. cathayensis); the two cultivated walnuts of section Juglans (J. regia and J. sigillata) were from Yunnan province, while J. regia of section Juglans and J. cathayensis of section Cardiocaryon were from the Qingling Mountains. Yunnan province is the most abundant area of biodiversity in China. This province harbors many rare, endemic, and ancient groups and is one of the most important focuses of global research and one of the key areas of biological diversity taxa distribution. The Qingling Mountains are rich in natural resources and are located in the transition zone between the temperate zone and subtropical zone in china, and therefore, have become an important biogeographical boundary in China. Studies have shown that the Qingling Mountains were one of the shelters for walnut plants during the glacial period [31-33].

In recent years, researchers have used different molecular genetic markers (RAPD, RFLP, ITS, cpDNA, SSR, and ISSR) to study the genetic relationship, phylogeography, and genetic structure of Juglans [27,28,30,34-43]. Simple sequence repeats (SSR) [34], with the advantage of high polymorphism and co-dominant inheritance, are increasingly used in walnut germplasm resources' research and the genetic study of many crops. Currently, hundreds of SSR primer pairs with high polymorphism are available to Juglans and have been demonstrated to be useful in many kinds of genetic analyses on walnut [23,31,37-41]. A previous molecular study used 12 microsatellite markers from samples of several individuals from three regions found in Hubei Province to identify the hybrids between $J$. regia and J. cathayensis; that study also suggested that hybridization between J. regia and J. cathayensis was rare [42]. The SSR data analysis method was also applied to J. regia and J. sigillata populations. The results revealed that introgression has occurred between the two species (J. regia and J. sigillata) in southwest China and the direction of gene flow is mainly from J. regia to J. sigillata [27,43].

In this study, we extended the sample group to cover more natural populations of three species and first explored the interspecific hybridization of Chinese Juglans plants, which provides a theoretical basis for the genetic evolution of the genus Juglans. We collected 656 individuals from 40 populations of sympatric J. regia and J. cathayensis in the Qinling Mountains and sympatric J. regia and J. sigillata in Yunnan Province that were genotyped at 17 expressed sequence tag simple sequence repeat (EST-SSR) loci to address the following two questions: (1) What is the genetic diversity and genetic structure of walnut plants, taking three species of Juglans as an example to explore the phenomenon of gene flow among closely related species in sympatric populations? (2) Are J. sigillata and J. regia completely different species or are they simply different ecological types? 


\section{Materials and Methods}

\subsection{Sampling, DNA Extraction, and PCR Amplification}

Leaves from 656 samples were collected from 40 typical populations of J. regia, J. cathayensis, and J. sigillata (details in Table 1; Figure 1$)$. In this group, 4 pairs of the sympatric $J$. regia $(n=58$, labeled with a Y-r postfix) and $J$. sigillata $(n=120$, labeled with a Y-s postfix) populations were from Yunnan province; 12 pairs of the sympatric J. regia $(n=183$, labeled with an r postfix) and J. cathayensis $(n=186$, labeled with a c postfix) populations were from the Qingling Mountains; 4 pairs of the sympatric J. regia ( $n=49$, labeled with an r postfix) and J. cathayensis ( $n=60$, labeled with a c postfix) populations were from the four other provinces, Sichuan, Yunnan, Gansu, and Henan. Samples were identified and collected according to the morphological characteristics (leaf, flower, fruit, nut, etc.) of the three Juglans species [17,25-30]. All fresh leaves were completely dried with silica gel, which followed the methods of Doyle and Doyle (1987) [44] and Zhao and Woeste (2011) [24], and were stored at $-20{ }^{\circ} \mathrm{C}$. Following DNA extraction, we further examined the gene flow of the three species via 17 pairs of polymorphic EST-SSR primers, which have been reported before (Table S1). All primers were synthesized and labeled with fluorescent dye, 6-FAM, TAMRA, or HEX by Sangon Biotech in Shanghai, China. PCR amplification was carried out on a SimpliAmp Thermal Cycler (Applied Biosystem, Hercules, CA, USA) in a $20 \mu \mathrm{L}$ reaction volumes $(10 \mu \mathrm{L} 2 \times$ PCR aaster mix, $0.4 \mu \mathrm{L}$ each primer, $2 \mu \mathrm{L}$ BSA, $2 \mu \mathrm{L}$ of $10 \mathrm{ng} / \mu \mathrm{L}$ DNA, and $5.2 \mu \mathrm{L} \mathrm{ddH}_{2} \mathrm{O}$ ). PCR amplifications were performed as follows: an initial denaturation step at $94{ }^{\circ} \mathrm{C}$ for $5 \mathrm{~min}$, followed by 30 cycles of $45 \mathrm{~s}$ at $94{ }^{\circ} \mathrm{C}, 30 \mathrm{~s}$ annealing temperature (Tm; Table S1), and $90 \mathrm{~s}$ at $72{ }^{\circ} \mathrm{C}$, and a final extension step at $72{ }^{\circ} \mathrm{C}$ for $5 \mathrm{~min}$. Fragment sizes were evaluated using GeneMapper v3.7 (Applied Biosystems) and were checked manually, twice, to reduce the scoring error.

\subsection{Microsatellite Data Analysis}

The evaluation of the genetic diversity for each locus and population was based on the following descriptive summary statistics: the number of alleles $(A)$, the number of effective alleles $(\mathrm{Ne})$, the observed $\left(H_{O}\right)$ and expected $\left(H_{E}\right)$ heterozygosity, the unbiased expected heterozygosity $\left(U H_{E}\right)$, the polymorphic information content $(P I C)$, the within-population inbreeding coefficient $\left(F_{I S}\right)$, the total population inbreeding coefficient $\left(F_{I T}\right)$, and the among-population genetic differentiation coefficient $\left(F_{S T}\right)$ using GenAlEx6.5 [45]. Allelic richness $(R s)$ and private allele richness $\left(P_{A R}\right)$ were calculated by rarefying to the minimum sample size across populations [46] (Tables S1 and S2). Subsequently, the expected heterozygosity $\left(H_{E}\right)$, the allelic richness $(R s)$, and the private allele richness $\left(P_{A R}\right)$ of the 40 populations sampled were used to show the geographic pattern by using the inverse distance weighted (IDW) interpolation function implemented in the Geographic Information System software ArcGIS 10.0 (ESRI, Redlands, CA, USA). The program, Arlequin version 3.5 [47], was used to analyze the molecular variance (AMOVA) of each species, among populations within species, and within populations among individuals. We calculated FST to identify the outlier loci potentially under selection [48]. Loci under selection pressure can bias the population's genetic analysis because most methods for evaluating genetic structure assume neutrality [49,50] ( $p \leq 0.05$; Figure S2). GENEPOP Version 4.2 [51] was used to test all loci of the Hardy-Weinberg equilibrium (HWE). Markers were also tested for the linkage disequilibrium (LD) at each population, and the locus was tested using FSTAT [52]. Significance was tested using 1000 permutations. CERVUS version 3.0 [53] was used to calculate the polymorphic information content (PIC). Each locus was evaluated for the possible presence of a null allele using MICRO-CHECKER 2.2.3 [54]. 
Table 1. Details of sample location, sample size, and descriptive statistics of genetic variability for 18 Juglans regia L. populations, four Juglans sigllata Dode populations, and 14 Juglans cathayensis Dode populations sampled in China.

\begin{tabular}{|c|c|c|c|c|c|c|c|c|c|c|c|c|c|c|}
\hline Order & Code & Species & Sample Site & Samples & Latitude & Longitude & $A$ & $\mathrm{Ne}$ & Ho & $H_{E}$ & $U H_{E}$ & $F_{I S}$ & Rs & $P_{A R}$ \\
\hline 1 & QS-r & J. regia & Qishan, Shaanxi & 28 & $34^{\circ} 26^{\prime} 36^{\prime \prime} \mathrm{N}$ & $107^{\circ} 37^{\prime} 16^{\prime \prime} \mathrm{E}$ & 3.706 & 2.069 & 0.456 & 0.422 & 0.430 & -0.092 & 2.780 & 0.010 \\
\hline 2 & HHG-r & J. regia & Honghe, Shaanxi & 12 & $34^{\circ} 16^{\prime} 27^{\prime \prime} \mathrm{N}$ & $107^{\circ} 44^{\prime} 59^{\prime \prime} \mathrm{E}$ & 3.059 & 1.923 & 0.450 & 0.415 & 0.433 & -0.088 & 2.870 & 0.020 \\
\hline 3 & HZ-r & J. regia & Hanzhong, Shaanxi & 4 & $32^{\circ} 37^{\prime} 01^{\prime \prime} \mathrm{N}$ & $107^{\circ} 24^{\prime} 29^{\prime \prime} \mathrm{E}$ & 1.941 & 1.596 & 0.324 & 0.250 & 0.286 & -0.284 & 1.940 & 0.000 \\
\hline 4 & BJ-r & J. regia & Baoji, Shaanxi & 15 & $34^{\circ} 21^{\prime} 36^{\prime \prime} \mathrm{N}$ & $107^{\circ} 52^{\prime} 12^{\prime \prime} \mathrm{E}$ & 2.294 & 1.631 & 0.203 & 0.304 & 0.315 & 0.266 & 2.110 & 0.000 \\
\hline 5 & NS-r & J. regia & Ankang, Shaanxi & 19 & $33^{\circ} 45^{\prime} 17^{\prime \prime} \mathrm{N}$ & $108^{\circ} 45^{\prime} 52^{\prime \prime} \mathrm{E}$ & 3.765 & 2.253 & 0.501 & 0.515 & 0.529 & 0.039 & 3.230 & 0.050 \\
\hline 6 & $\mathrm{HH}-\mathrm{r}$ & J. regia & Honghegu, Shaanxi & 12 & $34^{\circ} 16^{\prime} 12^{\prime \prime} \mathrm{N}$ & $108^{\circ} 57^{\prime} 00^{\prime \prime} \mathrm{E}$ & 2.118 & 1.555 & 0.208 & 0.288 & 0.301 & 0.293 & 2.030 & 0.050 \\
\hline 7 & LN-r & J. regia & Shangluo, Shaanxi & 20 & $34^{\circ} 05^{\prime} 27^{\prime \prime} \mathrm{N}$ & $110^{\circ} 08^{\prime} 55^{\prime \prime} \mathrm{E}$ & 2.882 & 1.809 & 0.350 & 0.374 & 0.384 & 0.039 & 2.440 & 0.000 \\
\hline 8 & LT-r & J. regia & Lantian, Shaanxi & 10 & $34^{\circ} 09^{\prime} 06^{\prime \prime} \mathrm{N}$ & $109^{\circ} 19^{\prime} 25^{\prime \prime} \mathrm{E}$ & 3.000 & 1.949 & 0.501 & 0.451 & 0.475 & -0.059 & 2.910 & 0.110 \\
\hline 9 & PL-r & J. regia & Pingli, Shaanxi & 14 & $32^{\circ} 23^{\prime} 24^{\prime \prime} \mathrm{N}$ & $109^{\circ} 21^{\prime} 36^{\prime \prime} \mathrm{E}$ & 2.471 & 1.723 & 0.290 & 0.322 & 0.335 & 0.125 & 2.290 & 0.000 \\
\hline 10 & SZ-r & J. regia & Shangluo, Shaanxi & 23 & $33^{\circ} 51^{\prime} 46^{\prime \prime} \mathrm{N}$ & $109^{\circ} 56^{\prime} 28^{\prime \prime} \mathrm{E}$ & 3.118 & 1.813 & 0.341 & 0.385 & 0.394 & 0.138 & 2.540 & 0.020 \\
\hline 11 & ZS-r & J. regia & Shangluo, Shaanxi & 15 & $33^{\circ} 31^{\prime} 48^{\prime \prime} \mathrm{N}$ & $109^{\circ} 52^{\prime} 48^{\prime \prime} \mathrm{E}$ & 2.059 & 1.619 & 0.263 & 0.300 & 0.310 & 0.169 & 2.010 & 0.010 \\
\hline 12 & SL-r & J. regia & Shangluo, Shaanxi & 11 & $33^{\circ} 41^{\prime} 45^{\prime \prime} \mathrm{N}$ & $110^{\circ} 19^{\prime} 38^{\prime \prime} \mathrm{E}$ & 3.000 & 2.020 & 0.566 & 0.436 & 0.457 & -0.282 & 2.840 & 0.000 \\
\hline 13 & EM-r & J. regia & Emei, Sichuan & 14 & $30^{\circ} 39^{\prime} 00^{\prime \prime} \mathrm{N}$ & $102^{\circ} 04^{\prime} 48^{\prime \prime} \mathrm{E}$ & 2.588 & 1.814 & 0.285 & 0.367 & 0.382 & 0.193 & 2.420 & 0.010 \\
\hline 14 & YN-r & J. regia & Wenshan, Yunnan & 12 & $23^{\circ} 24^{\prime} 00^{\prime \prime} \mathrm{N}$ & $104^{\circ} 13^{\prime} 12^{\prime \prime} \mathrm{E}$ & 2.529 & 1.791 & 0.226 & 0.366 & 0.383 & 0.398 & 2.430 & 0.000 \\
\hline 15 & GS-r & J. regia & Tianshui, Gansu & 9 & $34^{\circ} 18^{\prime} 00^{\prime \prime} \mathrm{N}$ & $106^{\circ} 03^{\prime} 00^{\prime \prime} \mathrm{E}$ & 2.059 & 1.596 & 0.215 & 0.291 & 0.310 & 0.231 & 2.060 & 0.060 \\
\hline 16 & HN-r & J. regia & Zhenzhou, Henan & 14 & $34^{\circ} 46^{\prime} 12^{\prime \prime} \mathrm{N}$ & $113^{\circ} 45^{\prime} 00^{\prime \prime} \mathrm{E}$ & 2.353 & 1.657 & 0.288 & 0.315 & 0.327 & 0.088 & 2.200 & 0.000 \\
\hline 17 & QZ-Y-r & J. regia & Qizong, Yunnan & 22 & $27^{\circ} 34^{\prime} 00^{\prime \prime} \mathrm{N}$ & $99^{\circ} 31^{\prime} 00^{\prime \prime} \mathrm{E}$ & 3.294 & 2.317 & 0.369 & 0.443 & 0.454 & 0.177 & 2.840 & 0.000 \\
\hline 18 & LM-Y-r & J. regia & Liming, Yunnan & 10 & $27^{\circ} 9^{\prime} 00^{\prime \prime} \mathrm{N}$ & $99^{\circ} 48^{\prime} 00^{\prime \prime} \mathrm{E}$ & 1.176 & 1.118 & 0.165 & 0.092 & 0.097 & -0.634 & 2.110 & 0.040 \\
\hline 19 & SG-Y-r & J. regia & Shigu, Yunnan & 11 & $26^{\circ} 52^{\prime} 00^{\prime \prime} \mathrm{N}$ & $99^{\circ} 57^{\prime} 00^{\prime \prime} \mathrm{E}$ & 2.529 & 1.747 & 0.278 & 0.335 & 0.352 & 0.201 & 2.440 & 0.060 \\
\hline \multirow[t]{2}{*}{20} & BS-Y-r & J. regia & Baoshan, Yunnan & 15 & $25^{\circ} 17^{\prime} 00^{\prime \prime} \mathrm{N}$ & $98^{\circ} 47^{\prime} 00^{\prime \prime} \mathrm{E}$ & 1.765 & 1.461 & 0.249 & 0.251 & 0.261 & 0.033 & 2.660 & 0.000 \\
\hline & Average & & & & & & 2.585 & 1.773 & 0.326 & 0.346 & 0.361 & 0.048 & 2.458 & 0.022 \\
\hline 21 & QZ-Y-s & J. sigllata & Qizong, Yunnan & 30 & $27^{\circ} 34^{\prime} 00^{\prime \prime} \mathrm{N}$ & $99^{\circ} 31^{\prime} 00^{\prime \prime} \mathrm{E}$ & 3.176 & 2.183 & 0.346 & 0.387 & 0.394 & 0.150 & 3.510 & 0.010 \\
\hline 22 & LM-Y-s & J. sigllata & Liming, Yunnan & 30 & $27^{\circ} 9^{\prime} 00^{\prime \prime} \mathrm{N}$ & $99^{\circ} 48^{\prime} 00^{\prime \prime} \mathrm{E}$ & 2.882 & 2.077 & 0.387 & 0.367 & 0.374 & -0.030 & 3.230 & 0.050 \\
\hline 23 & SG-Y-s & J. sigllata & Shigu, Yunnan & 30 & $26^{\circ} 52^{\prime} 00^{\prime \prime} \mathrm{N}$ & $99^{\circ} 57^{\prime} 00^{\prime \prime} \mathrm{E}$ & 2.353 & 1.604 & 0.258 & 0.312 & 0.317 & 0.193 & 2.900 & 0.000 \\
\hline \multirow[t]{2}{*}{24} & BS-Y-s & J. sigllata & Yongping, Yunnan & 30 & $25^{\circ} 27^{\prime} 00^{\prime \prime} \mathrm{N}$ & $99^{\circ} 32^{\prime} 00^{\prime \prime} \mathrm{E}$ & 2.294 & 1.418 & 0.336 & 0.254 & 0.259 & -0.215 & 2.730 & 0.000 \\
\hline & Average & & & & & & 2.676 & 1.821 & 0.332 & 0.33 & 0.336 & 0.025 & 3.093 & 0.015 \\
\hline 25 & BY-c & J. cathayensis & Baoji, Shaanxi & 21 & $34^{\circ} 26^{\prime} 36^{\prime \prime} \mathrm{N}$ & $107^{\circ} 37^{\prime} 16^{\prime \prime} \mathrm{E}$ & 4.765 & 2.780 & 0.476 & 0.515 & 0.527 & 0.211 & 3.820 & 0.040 \\
\hline 26 & GX-c & J. cathayensis & Baoji, Shaanxi & 16 & $34^{\circ} 21^{\prime} 47^{\prime \prime} \mathrm{N}$ & $107^{\circ} 14^{\prime} 16^{\prime \prime} \mathrm{E}$ & 4.471 & 2.978 & 0.475 & 0.458 & 0.473 & 0.057 & 3.860 & 0.090 \\
\hline 27 & $\mathrm{HZ}-\mathrm{c}$ & J. cathayensis & Hanzhong, Shaanxi & 20 & $32^{\circ} 37^{\prime} 01^{\prime \prime} \mathrm{N}$ & $107^{\circ} 24^{\prime} 29^{\prime \prime} \mathrm{E}$ & 4.824 & 2.923 & 0.487 & 0.486 & 0.499 & 0.037 & 3.830 & 0.050 \\
\hline 28 & $\mathrm{BJ}-\mathrm{C}$ & J. cathayensis & Baoji, Shaanxi & 9 & $34^{\circ} 21^{\prime} 33^{\prime \prime} \mathrm{N}$ & $107^{\circ} 52^{\prime} 30^{\prime \prime} \mathrm{E}$ & 3.412 & 2.226 & 0.434 & 0.441 & 0.468 & 0.041 & 3.400 & 0.000 \\
\hline 29 & NS-c & J. cathayensis & Ankang, Shaanxi & 18 & $33^{\circ} 32^{\prime} 60^{\prime \prime} \mathrm{N}$ & $108^{\circ} 32^{\prime} 58^{\prime \prime} \mathrm{E}$ & 4.353 & 2.658 & 0.481 & 0.484 & 0.498 & 0.016 & 3.570 & 0.030 \\
\hline 30 & $\mathrm{HH}-\mathrm{c}$ & J. cathayensis & Honghe, Shaanxi & 24 & $34^{\circ} 15^{\prime} 56^{\prime \prime} \mathrm{N}$ & $108^{\circ} 57^{\prime} 16^{\prime \prime} \mathrm{E}$ & 5.706 & 3.134 & 0.527 & 0.497 & 0.508 & -0.033 & 4.060 & 0.020 \\
\hline 31 & LN-c & J. cathayensis & Shangluo, Shaanxi & 19 & $34^{\circ} 15^{\prime} 56^{\prime \prime} \mathrm{N}$ & $108^{\circ} 57^{\prime} 16^{\prime \prime} \mathrm{E}$ & 3.412 & 2.024 & 0.452 & 0.411 & 0.423 & -0.093 & 2.930 & 0.010 \\
\hline 32 & LT-c & J. cathayensis & Lantian, Shaanxi & 5 & $34^{\circ} 09^{\prime} 06^{\prime \prime} \mathrm{N}$ & $109^{\circ} 19^{\prime} 25^{\prime \prime} \mathrm{E}$ & 3.882 & 3.153 & 0.552 & 0.611 & 0.698 & 0.095 & 3.880 & 0.160 \\
\hline
\end{tabular}


Table 1. Cont.

\begin{tabular}{|c|c|c|c|c|c|c|c|c|c|c|c|c|c|c|}
\hline Order & Code & Species & Sample Site & Samples & Latitude & Longitude & $A$ & $\mathrm{Ne}$ & Но & $H_{E}$ & $U H_{E}$ & $F_{I S}$ & $R s$ & $P_{A R}$ \\
\hline 33 & PL-c & J. cathayensis & Ankang, Shaanxi & 18 & $32^{\circ} 23^{\prime} 20^{\prime \prime} \mathrm{N}$ & $109^{\circ} 21^{\prime} 43^{\prime \prime} \mathrm{E}$ & 5.353 & 3.210 & 0.506 & 0.499 & 0.513 & 0.030 & 4.260 & 0.080 \\
\hline 34 & SZ-c & J. cathayensis & Shangluo, Shaanxi & 10 & $33^{\circ} 51^{\prime} 38^{\prime \prime} \mathrm{N}$ & $109^{\circ} 52^{\prime} 43^{\prime \prime} \mathrm{E}$ & 3.588 & 2.400 & 0.481 & 0.467 & 0.493 & 0.070 & 3.480 & 0.000 \\
\hline 35 & ZS-c & J. cathayensis & Shangluo, Shaanxi & 15 & $33^{\circ} 31^{\prime} 56^{\prime \prime} \mathrm{N}$ & $109^{\circ} 52^{\prime} 56^{\prime \prime} \mathrm{E}$ & 3.706 & 2.268 & 0.506 & 0.467 & 0.484 & -0.063 & 3.290 & 0.030 \\
\hline 36 & SL-C & J. cathayensis & Shangluo, Shaanxi & 11 & $33^{\circ} 27^{\prime} 49^{\prime \prime} \mathrm{N}$ & $110^{\circ} 26^{\prime} 30^{\prime \prime} \mathrm{E}$ & 3.647 & 2.483 & 0.473 & 0.462 & 0.484 & 0.014 & 3.400 & 0.000 \\
\hline 37 & EM-c & J. cathayensis & Baoxing, Sichuan & 9 & $30^{\circ} 22^{\prime} 05^{\prime \prime} \mathrm{N}$ & $102^{\circ} 48^{\prime} 52^{\prime \prime} \mathrm{E}$ & 3.294 & 2.158 & 0.399 & 0.404 & 0.428 & -0.007 & 3.240 & 0.060 \\
\hline 38 & YN-c & J. cathayensis & Wenshan, Yunnan & 11 & $23^{\circ} 24^{\prime} 02^{\prime \prime} \mathrm{N}$ & $104^{\circ} 12^{\prime} 58^{\prime \prime} \mathrm{E}$ & 3.471 & 2.463 & 0.494 & 0.507 & 0.532 & -0.014 & 3.340 & 0.120 \\
\hline 39 & GS-c & J. cathayensis & Tianshui, Gansu & 20 & $34^{\circ} 34^{\prime} 13^{\prime \prime} \mathrm{N}$ & $105^{\circ} 53^{\prime} 22^{\prime \prime} \mathrm{E}$ & 4.588 & 2.664 & 0.426 & 0.431 & 0.442 & 0.056 & 3.570 & 0.080 \\
\hline \multirow[t]{2}{*}{40} & $\mathrm{HN}-\mathrm{C}$ & J. cathayensis & Linzhou, Henan & 20 & $36^{\circ} 04^{\prime} 59^{\prime \prime} \mathrm{N}$ & $113^{\circ} 49^{\prime} 12^{\prime \prime} \mathrm{E}$ & 3.765 & 2.430 & 0.436 & 0.446 & 0.457 & 0.023 & 3.290 & 0.080 \\
\hline & Average & & & & & & 4.140 & 2.622 & 0.475 & 0.474 & 0.495 & 0.028 & 3.576 & 0.053 \\
\hline
\end{tabular}

Note: Each population's total number of alleles $(A)$, number of effective alleles $(\mathrm{Ne})$, observed $(\mathrm{Ho})$ and expected $\left(H_{E}\right)$ heterozygosity, unbiased expected heterozygosity $\left(U H_{E}\right)$, inbreeding coefficient $\left(F_{I S}\right)$, allelic richness $(R s)$, and private allele richness $\left(P_{A R}\right)$. 
(a)

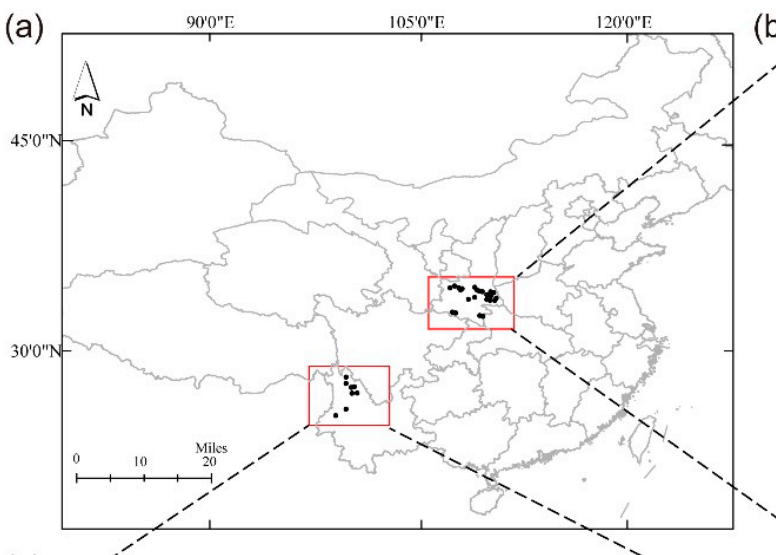

(c)

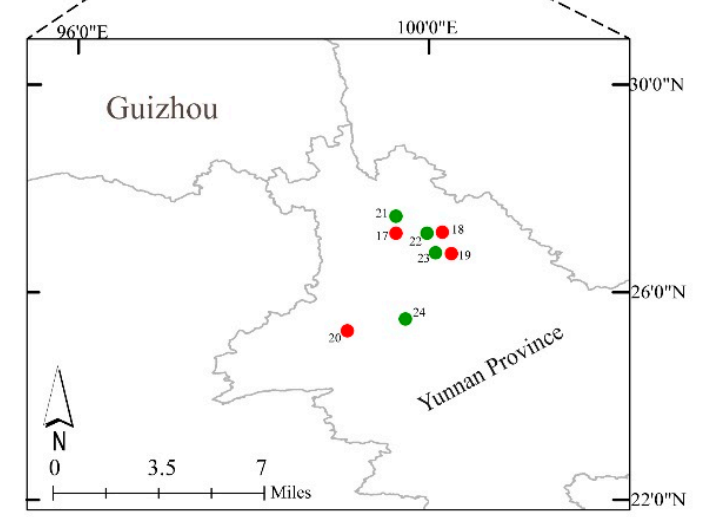

(b)

$1080^{\circ} \mathrm{E}$

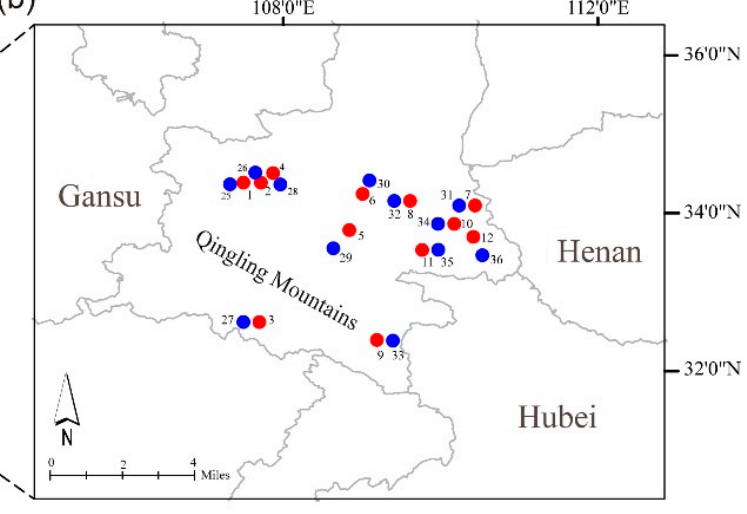

- J. regia population from QL and $\mathrm{YN}$

- $J$. cathayensis population from QL

- J. sigllata population fromYN

Figure 1. The sample collection information for the three walnuts. (a) A total of 656 trees from 40 sites of sympatric Juglans regia and J. cathayensis in the Qinling Mountains and sympatric J. regia and J. sigillata in Yunnan Province. The black dots indicate the population locations. (b) The map information for a total of 369 samples from 24 populations from the Qingling Mountains. The red dots and blue dots indicate the locations of the sympatric J. regia (183 individuals) and J. cathayensis (186 individuals), respectively. (c) The map information for a total of 178 samples of 8 populations from the Qingling Mountains. The red dots and green dots indicate the locations of the sympatric J. regia (58 individuals) and J. sigillata (120 individuals) populations, respectively.

Genetic structure analysis was implemented in STRUCTURE version 2.3.4 using a Bayesian clustering approach [55]. A total of nine independent simulations were run for each $K(1-10)$, with 50,000 burn-in steps followed by 100,000 MCMC steps, using the LOCPRIOR model (admixture model with sample locations as prior information) with dependent allele frequencies. The program STRUCTURE HARVESTER was used to calculate the optimal value of $K$ using the delta $K$ criterion [56], while the inferred clusters were drawn as colored box plots using the program DISTRUCT [57]. GenAlEx 6.5 was used for principal coordinate analysis $(P C O A)$ to explore the overall genetic variation of the EST-SSR data. The unweighted pair-group method with an arithmetic means (UPGMA) tree based on Nei's genetic distance [58] was utilized using POPTREE2 [59] and visualized with the software Fig Tree 1.4.2 [60]. MIGRATE 3.6.4 [61] was used to estimate the historical gene flow parameter (M) and the frequency of migration events through the coalescent history between sympatric J. regia and J. sigillata populations in Yunnan Province and J. regia and J. cathayensis populations in the Qinling Mountains for the EST-SSRs. The mode and $95 \%$ highest posterior density were then estimated after checking for data convergence. 


\section{Results}

\subsection{Nuclear Microsatellite Diversity}

Genetic diversity estimates varied among the microsatellite loci (Table S1) and among the population (Table 1). The allelic diversity across the loci was highly polymorphic and is summarized in Table S1. Most loci showed a significant departure from the Hardy-Weinberg equilibrium (HWE) test, which was performed for all individuals using Genepop with 1000 permutations. A total of 55 alleles were detected over the 17 loci among the 656 sampled individuals, with the total number of alleles (A) per locus ranging from 2 to 7 and having a mean of 3.22 (Table S1). Locus JR1817 had the largest number of alleles $(\mathrm{A}=7)$. A private allele was identified at a high frequency $(0.19)$ at the GS-r sample site. The observed $(H o)$ and expected $\left(H_{E}\right)$ heterozygosity varied from 0.117 to 0.668 and from 0.135 to 0.671 , with averages of 0.386 and 0.396 , respectively (Table S1). The within-population inbreeding coefficient $\left(F_{I S}\right)$ was significantly negative for JC8125, JH89978, JM5969, JR4616, JH42753, JH86514, JH6044, and JH2096, and was significantly positive for the remaining nine loci. An $F_{I S}$ value significantly greater than zero indicated heterozygote deficiency, which may be the result of the inbreeding extent of the larger population. The inbreeding coefficient was determined $\left(F_{I T}\right)$ at each locus, ranging from 0.107 to 0.784 , with an average of 0.441 . The genetic differentiation $\left(F_{S T}\right)$ ranged from 0.188 to 0.77 , with a mean of 0.429 , indicating strong genetic differentiation among the populations (Table S1). Eight of the seventeen loci were detected to be $F_{\text {ST }}$ outliers: JC3412, JM5969, JC7329, JR4964, JR4616, JM78331, JR6160, and JR1817 (Figure S2).

\subsection{Genetic Diversity within and among Juglans Population}

Genetic diversity estimates for each population based on the 17 EST-SSRs are reported in Table 1. The values of the $A, \mathrm{Ne}, \mathrm{Ho}, \mathrm{H}_{E}, U H_{E}, \mathrm{Rs}$, and $P_{A R}$ of each population ranged from 1.176 to 5.706, 1.118 to $3.21,0.165$ to $0.566,0.092$ to $0.611,0.097$ to $0.698,1.960$ to 4.260 , and 0.000 to 0.160 , respectively (Table 1). Overall, $F_{I S}$ ranged from -0.634 (18-LM-Y-r) to 0.398 (14-YN-r), which was significantly greater than zero in 27 of 40 sampled sites, indicating a surplus of homozygotes in 14, 2, and 11 of J. regia, J. cathayensis, and J. sigillata, respectively. Figures 2 and 3 display, geographically, the values of the expected heterozygosity $\left(H_{E}\right)$, the allelic richness $(R s)$, and the private allele richness $\left(P_{A R}\right)$ reported in Table 1. The geospatial interpolation of these indices enables us to better compare the new spatial data representing the genetic diversity of sympatric J. regia versus J. cathayensis populations in Qinling Mountains and sympatric J. regia versus J. sigillata populations in Yunnan Province (Figure 2 versus Figure 3). In the Qinling Mountains, the expected heterozygosity $\left(H_{E}\right)$ values of J. regia and J. cathayensis ranged from 0.25 (3-HZ-r) to 0.52 (5-NS-r) and 0.41 (31-LN-c) to 0.61 (32-LT-c), respectively (Table 1). A high value of $H_{E}$ was observed in the J. regia populations located in the central, western, and eastern parts of the Qinling Mountains (Figure 2a), while high values of $H_{E}$ were taken from the central and western parts of the Qinling Mountains of J. cathayensis populations (Figure 2b). The difference was that lower values of $H_{E}$ appeared in the J. cathayensis populations from the eastern Qinling Mountains. High values of allelic richness $(R s)$ and $H_{E}$ showed the same distribution areas in J. regia populations and J. cathayensis populations (Figure 2c,d). However, the western and eastern parts of the Qinling Mountains in J regia populations revealed lower values for the private allele richness $\left(P_{A R}\right)$, which was inconsistent with the results of $H_{E}$ and $R s$ (Figure 2e). The difference was that the $P_{A R}$ results of the J. cathayensis populations showed the same trends as those of $H_{E}$ and $R s$ (Figure 2f). In Yunnan Province, the expected heterozygosity $\left(H_{E}\right)$ values of $J$. regia and J. sigillata ranged from 0.10 (18-LM-Y-r) to 0.43 (17-QZ-Y-r) and from 0.25 (24-BS-Y-s) to 0.39 (21-QZ-Y-s), respectively (Table 1). For J. sigillata, higher values of $H_{E}, R s$, and $P_{A R}$ were observed in northern Yunnan, while some of the populations from south Yunnan province had the lowest numbers (Figure 3b,d,f). For J. regia, a high value of $H_{E}$ was found in northern Yunnan (Figure 3a). Interestingly, the result of $R s$ in J. regia populations from Yunnan Province was the opposite of the $P_{A R}$ result (Figure 3c,e). AMOVA showed that the percentage of variation and the coefficient of genetic differentiation at these loci $\left(F_{S T}\right)$, between J. regia and J. sigillata, J. regia, and 
J. cathayensis, was $26.53 \%(p<0.001), 33.77 \%(p<0.001)$, and $0.406(p<0.001)$ and $0.412(p<0.001)$, demonstrating that the difference between J. regia and J. cathayensis was significantly higher than that of J. regia and J. sigillata (Table 2). The AMOVA results of J. regia, J. sigillata, and J. cathayensis species showed that the proportion of variance mainly existed within populations (J. regia 79\%, p<0.001; J. sigillata 88\%, $p<0.001 ;$ J. cathayensis 88\%, $p<0.001$ ) (Table 2). The Migraten analysis produced $\theta$ and $M$ values greater than zero. The $\theta$-value and the size of the immigration rate $(M)$ revealed a highly asymmetric historical gene flow among the three species. The results of the historical gene flow analysis indicate that J. regia and J. sigillata have no genetic barriers, and the directional gene flow is mainly from J. regia to J. sigillata (4.63 versus 2.19) (Table 3). J. regia and J. cathayensis populations in the Qinling Mountains showed lower historical gene flow (0.85 versus 0.93) (Table 3).
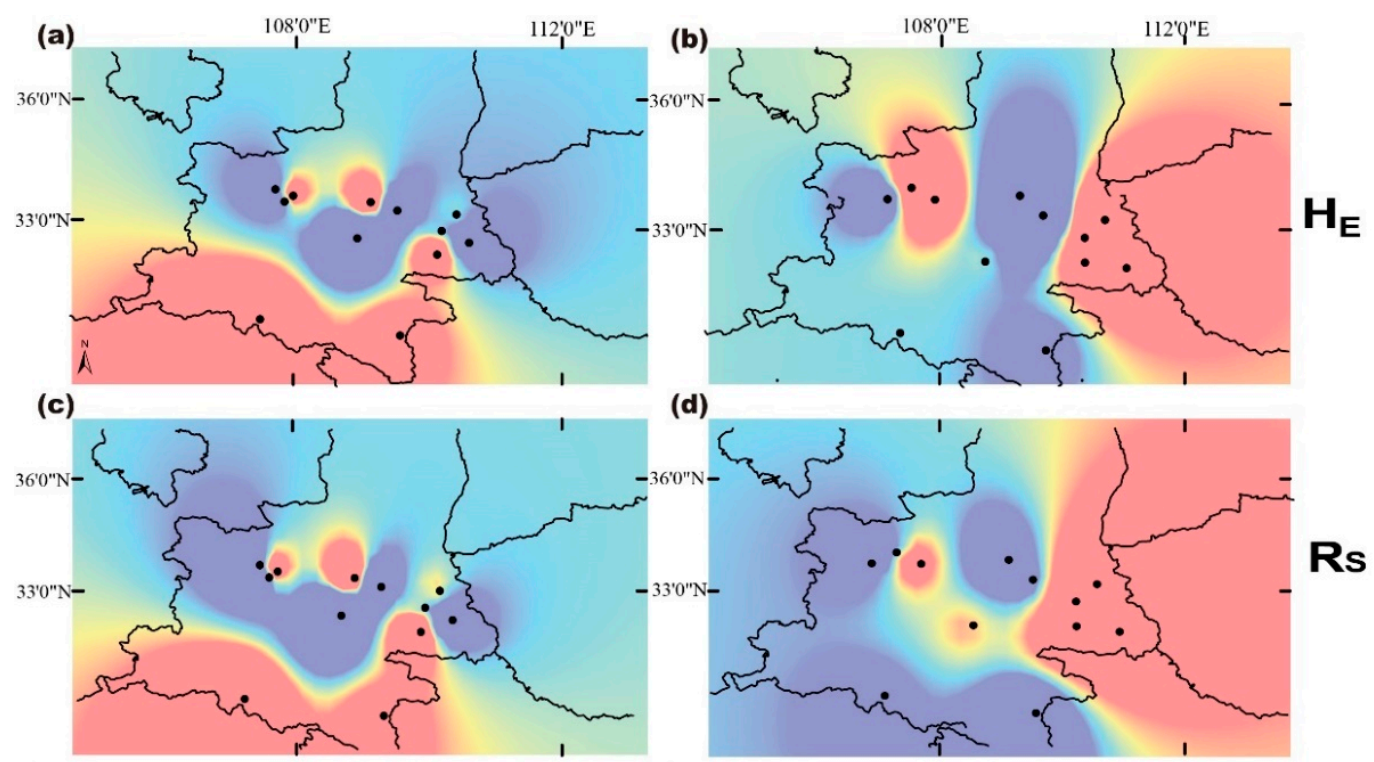

(d)

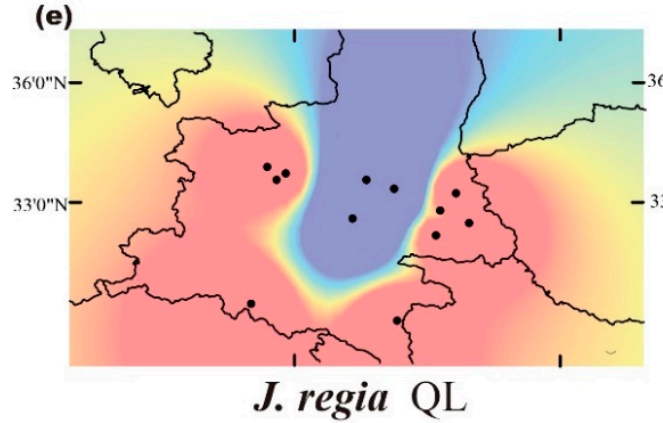

(f)

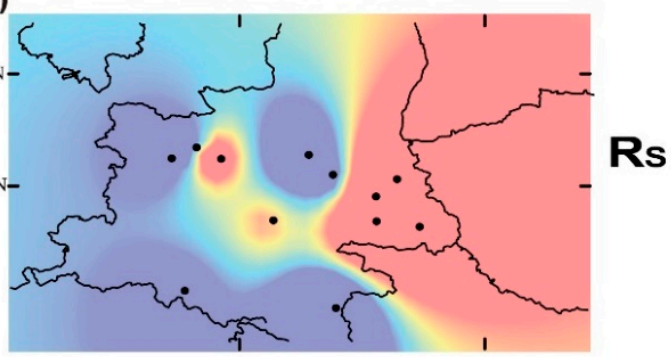

Figure 2. Inverse distance weighted (IDW) interpolation of the expected heterozygosity $\left(H_{E}\right)$, the allelic richness $(R s)$, and the private allele richness $\left(P_{A R}\right)$ for the 24 populations (black dots; 12 pairs of the sympatric J. regia and J. cathayensis populations) from the the Qingling Mountains using 17 expressed sequence tag simple sequence repeat (EST-SSR) markers. The numbers of walnut populations are shown in Table 1. IDW interpolation of (a,c,e) expected heterozygosity $\left(H_{E}\right)$, allelic richness $(R s)$, and private allele richness $\left(P_{A R}\right)$ values of $J$. regia; $(\mathbf{b}, \mathbf{d}, \mathbf{f})$ expected heterozygosity $\left(H_{E}\right)$, allelic richness $(R s)$, and private allele richness $\left(P_{A R}\right)$ values of $J$. cathayensis. 


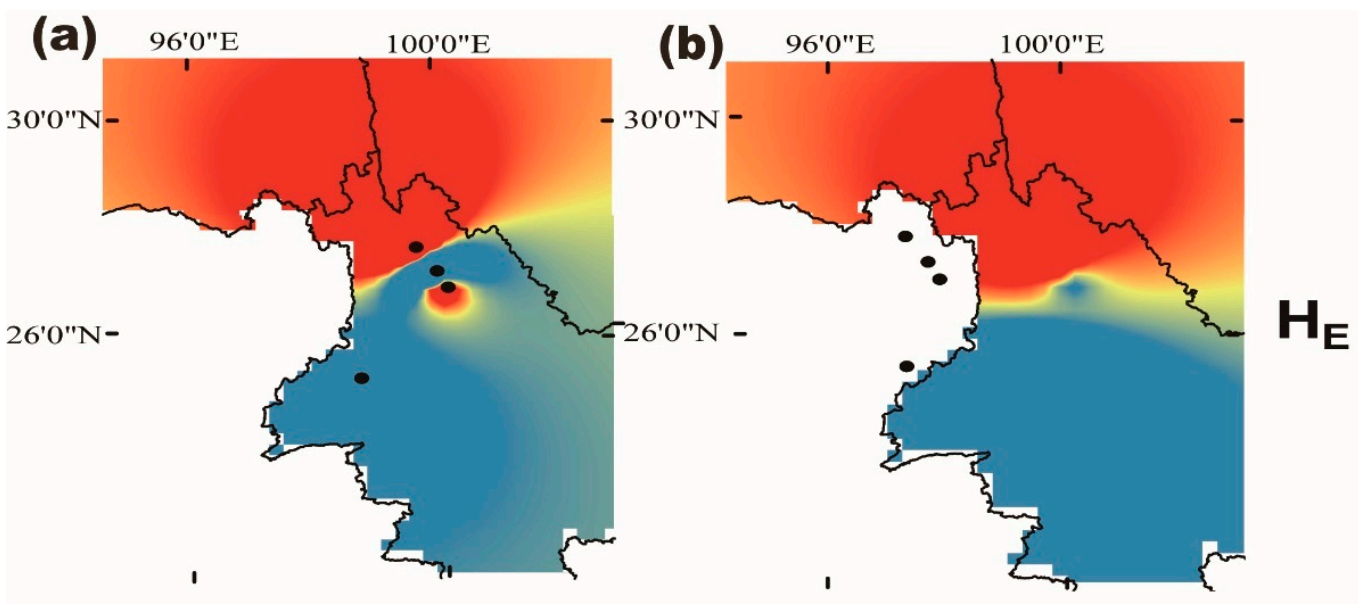

(c)

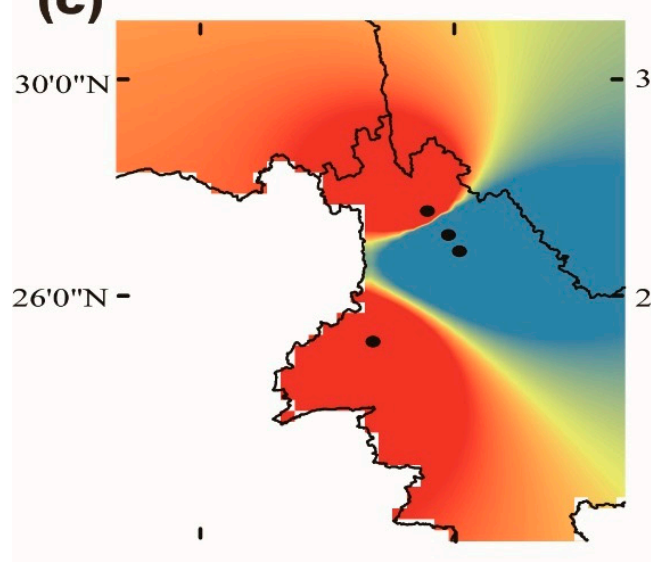

(e)

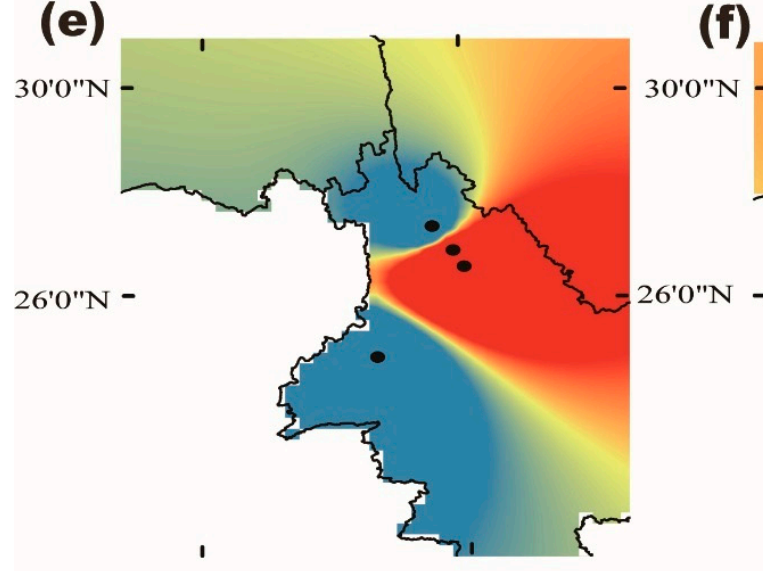

J. regia $\mathrm{YN}$ (d)

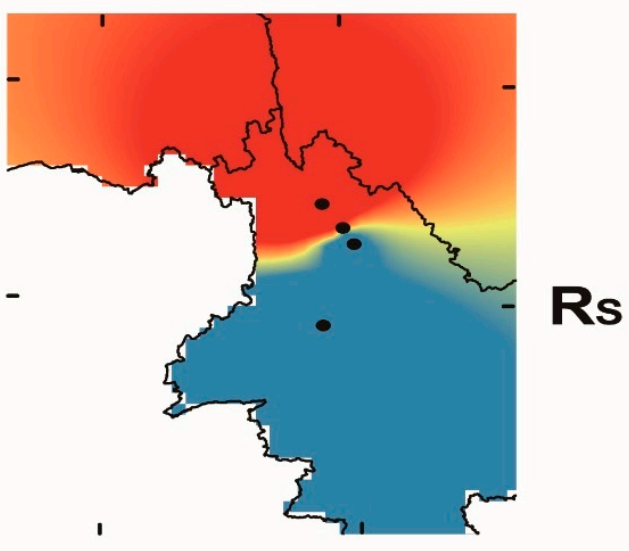

(f)

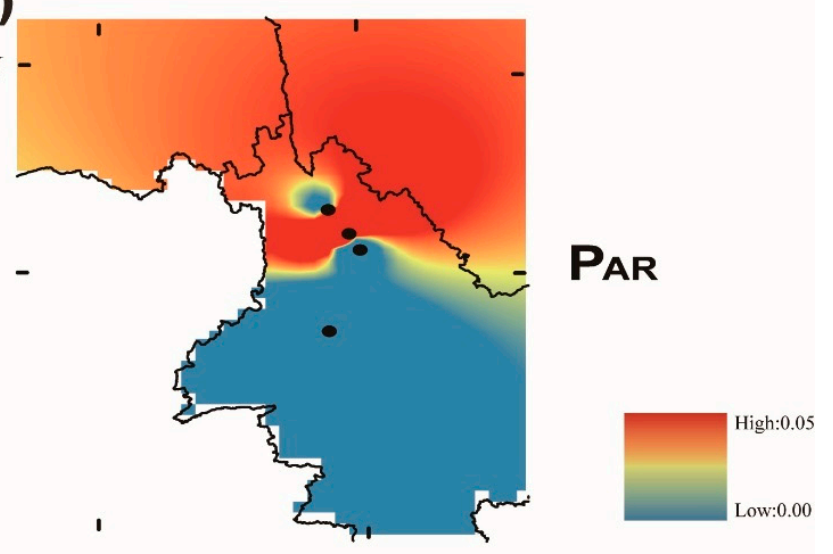

J. sigillata YN

Figure 3. IDW interpolation of the expected heterozygosity $(\mathrm{He})$, the allelic richness $(\mathrm{Rs})$, and the private allele richness $\left(P_{A R}\right)$ for the eight populations (black dots; four pairs of the sympatric J. regia and J. sigillata populations) from Yunnan province using 17 EST-SSR markers. The numbers of walnut populations are shown in Table 1. IDW interpolation of $(\mathbf{a}, \mathbf{c}, \mathbf{e})$ expected heterozygosity $(\mathrm{He})$, allelic richness $(R s)$, and private allele richness $\left(P_{A R}\right)$ values of $J$. regia; $(\mathbf{b}, \mathbf{d}, \mathbf{f})$ expected heterozygosity $(\mathrm{He})$, allelic richness $(R s)$, and private allele richness $\left(P_{A R}\right)$ values of $J$. sigillata. 
Table 2. Hierarchical analyses of molecular variance (AMOVA) of walnut samples based on 17 EST-SSR loci.

\begin{tabular}{|c|c|c|c|c|c|c|}
\hline Species & Source of Variation & d.f. & SS & Variance & $\%$ Vari. & Fixation Indices \\
\hline \multirow{4}{*}{$J R-J S-J C$} & Between species & 2 & 2008.942 & 2.34272 & 34.76 & $\mathrm{~F}_{\mathrm{ST}}=0.45360 * * *$ \\
\hline & Among populations Within species & 37 & 984.098 & 0.71572 & 10.61 & $\mathrm{~F}_{\mathrm{SC}}=0.16267^{* * *}$ \\
\hline & within populations & 1272 & 4686.325 & 3.68422 & 54.64 & $\mathrm{~F}_{\mathrm{CT}}=0.34745^{* * *}$ \\
\hline & Total & 1311 & 7679.365 & 6.74266 & & \\
\hline \multirow[t]{4}{*}{ JR-JS-Yunnan } & Between species & 1 & 244.793 & 1.35585 & 26.53 & $\mathrm{~F}_{\mathrm{ST}}=0.40647^{* * *}$ \\
\hline & Among populations Within species & 6 & 208.591 & 0.72137 & 14.12 & $\mathrm{~F}_{\mathrm{SC}}=0.19213^{* * *}$ \\
\hline & within populations & 348 & 1055.561 & 3.03322 & 59.35 & $\mathrm{~F}_{\mathrm{CT}}=0.26531 * * *$ \\
\hline & Total & 355 & 1508.944 & 5.11044 & & \\
\hline \multirow[t]{4}{*}{ JR-JC-Qingling } & Between species & 1 & 870.176 & 2.29901 & 33.77 & $\mathrm{~F}_{\mathrm{ST}}=0.41257 * * *$ \\
\hline & Among populations Within species & 22 & 428.294 & 0.50963 & 7.49 & $\mathrm{~F}_{\mathrm{SC}}=0.11303^{* * *}$ \\
\hline & within populations & 714 & 2855.330 & 3.99906 & 58.74 & $\mathrm{~F}_{\mathrm{CT}}=0.33771^{* * *}$ \\
\hline & Total & 737 & 4153.799 & 6.80770 & & \\
\hline \multirow[t]{3}{*}{$J R$} & Among populations & 19 & 562.123 & 0.90989 & 21.15 & $\mathrm{~F}_{\mathrm{ST}}=0.21148^{* * *}$ \\
\hline & within populations & 560 & 1899.880 & 3.39264 & 78.85 & \\
\hline & Total & 579 & 2462.003 & 4.30253 & & \\
\hline \multirow[t]{3}{*}{ JS } & Among populations & 3 & 84.600 & 0.41880 & 12.00 & $\mathrm{~F}_{\mathrm{ST}}=0.11997^{* * *}$ \\
\hline & Within populations & 236 & 725.017 & 3.07210 & 88.00 & \\
\hline & Total & 239 & 809.617 & 3.49090 & & \\
\hline \multirow[t]{3}{*}{ JC } & Among populations & 15 & 337.374 & 0.59536 & 12.09 & $F_{S T}=0.12086^{* * *}$ \\
\hline & Within populations & 476 & 2061.428 & 4.33073 & 87.91 & \\
\hline & Total & 491 & 2398.803 & 4.92609 & & \\
\hline
\end{tabular}

JR-J. regia, JS-J. sigillata, and JC-J. cathayensis; d.f., degrees of freedom; SS, sum of squares; Variance, ariance components; \% Vari., percentage of variation; $\mathrm{F}_{\mathrm{ST}}$, variance among populations; $\mathrm{F}_{\mathrm{SC}}$, variance within populations within groups; $\mathrm{F}_{\mathrm{CT}}$; variance among groups relative to total variance. ${ }^{* * *} p<0.001$. 
Table 3. Estimated gene flow between sympatric J. regia and J. sigillata populations in Yunnan Province and J. regia and J. cathayensis populations in Qinling Mountains by Migtate 3.6.4.

\begin{tabular}{|c|c|c|c|}
\hline & \multicolumn{3}{|c|}{$M(\mathrm{~m} / \mu)$} \\
\hline & $\theta$ & J. Regia $\rightarrow$ & J. Sigillata $\rightarrow$ \\
\hline J. regia & 1.85 (1.69-2.04) & & $2.19(1.86-2.57)$ \\
\hline \multirow[t]{3}{*}{ J. sigillata } & $1.03(0.96-1.10)$ & $4.63(4.03-5.30)$ & \\
\hline & & $M(\mathrm{~m} / \mu)$ & \\
\hline & $\theta$ & J. Regia $\rightarrow$ & J. Cathayensis $\rightarrow$ \\
\hline J. regia & 1.99 (1.89-2.09) & & $0.93(0.78-1.10)$ \\
\hline J. cathayensis & $4.18(3.98-4.39)$ & $0.85(0.74-0.98)$ & \\
\hline
\end{tabular}

$\theta$ is four times the effective population size multiplied by mutation rate per site per generation; $M$ is the immigration rate divided by the mutation rate.

\subsection{Population Structure of J. regia, J. cathayensis and J. sigillata}

According to the whole-range STRUCTURE analysis using three datasets (based on all three walnut species, only sympatric $J$. regia versus $J$. cathayensis populations and J. regia versus J. sigillata populations), the values of the log-likelihood of the data, loge $\operatorname{Pr}(\mathrm{K})$, increased progressively with an increase in $\mathrm{K}$, but delta $\mathrm{K}$ indicated that the optimal values for $\mathrm{K}$ were all 2 [55,62] (Figure S3a-c). The proportions of each individual in each population that were assigned into two clusters (clusters I and II) are shown in Figure 4. When all samples (from all three walnut species) were included in the STRUCTURE analysis (which was based on the EST-SSR data), the highest mean posterior probability value was detected for $K=2$ (Figure $4 \mathrm{~b}$ ). At $K=2$, all J. regia and J. sigillata populations were clustered into one group, and the J. cathayensis populations into the other. According to Nei's genetic distances, a phylogenetic tree was established by the unweighted pair-group method with arithmetic means (UPGMA) methods (Figure 4c). Figure 3c shows that three Juglans species were clustered into two branches. Cluster I included all J. regia and J. sigillata populations, in which the J. sigillata populations were classified as J. regia populations; the other consisted of J. cathayensis populations. In addition, the PCoA (Figure 4e), based on genetic distance, showed a similar genetic structure to that detected by the STRUCTURE analysis (Figure 4 b). For three species of Juglans, all the above results indicate that gene introgression is common among the same groups of Juglans, as only rare and low-level gene introgression appeared in distinct groups.

For sixteen pairs with sympatric distributions of J. regia and J. cathayensis from all of sampling regions, the $\Delta K$ values [62] computed for all $K$ classes indicated a strong signal for $K=2$ (Figure 4a and Figure S4b). The Bayesian clustering approach revealed that cluster I was the J. regia populations across 16 populations (1-12 populations from the Qinling Mountains and 13-16 populations from the four other provinces, Sichuan, Yunnan, Gansu, and Henan), while cluster II was the J. cathayensis populations (25-36 pop from the Qinling Mountains and 37-40 pop from the four other provinces). The results of the STRUCTURE analysis using twelve pairs of sympatric distribution of J. regia and J. cathayensis from the Qinling Mountains were in accordance with the genetic structures of all the populations and indicated little gene introgression or hybridization (Figure $5 b$ ). The negative correlation between pollen dispersal distance and population density has been reported in many wind-driven forest species [63,64]. Therefore, the high-density distribution of Juglans may, to some extent, limit the pollen dispersion distance. Subsequently, we used the four pairs of sympatric J. regia and J. cathayensis populations (1-QL-r versus 25-BY-c; 5-NS-r versus 29-NS-c; 8-LT-r versus 32-LT-c; 12-SL-r versus 36-SL-c), with relatively greater gene flow, to carry out the structure analysis, and the optimal $K$ value was 2 (Figure $5 \mathrm{~d}-\mathrm{g}$ ). The overall proportions of hybrids estimated by the four results of the STRUCTURE analysis were $4.08 \%(2 / 49), 5.41 \%(2 / 37)$, and $6.66 \%(1 / 15)$, respectively. In summary, only rare and low-level gene introgression occurred between sympatric J. regia and J. cathayensis populations. 


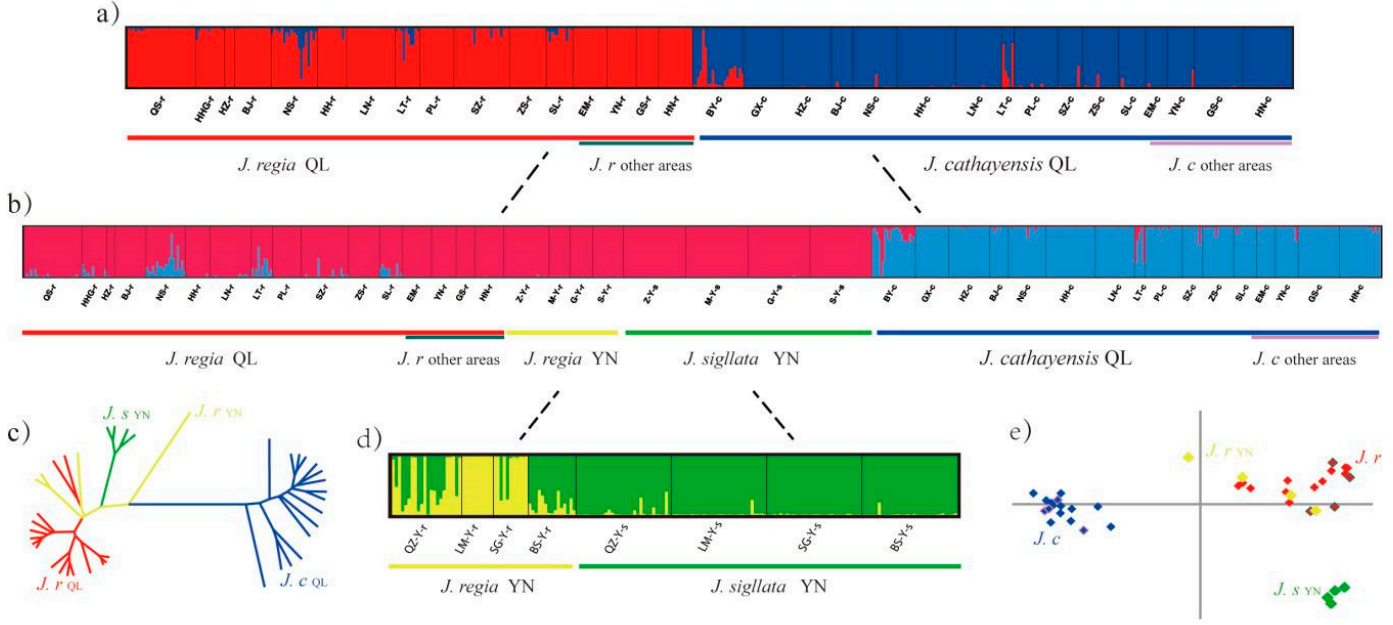

Figure 4. Genetic clustering of all individuals of J. regia, J. cathayensis and J. sigillata. (a,d) Population cluster analysis of the sympatric J. regia versus J. cathayensis populations and J. regia versus J. sigillata populations using STRUCTURE $(K=2)$ based on the EST-SSR datasets. (b) Population cluster analysis of three walnut species using STRUCTURE $(K=2)$ based on the EST-SSR datasets. (c) The UPGMA tree of all individuals from the three Juglans species based on Nei's genetic distance. (e) Principal coordinate analyses $(P C O A)$ of all individuals of 40 Juglans populations resolved into three genotype groups based on the EST-SSR datasets.

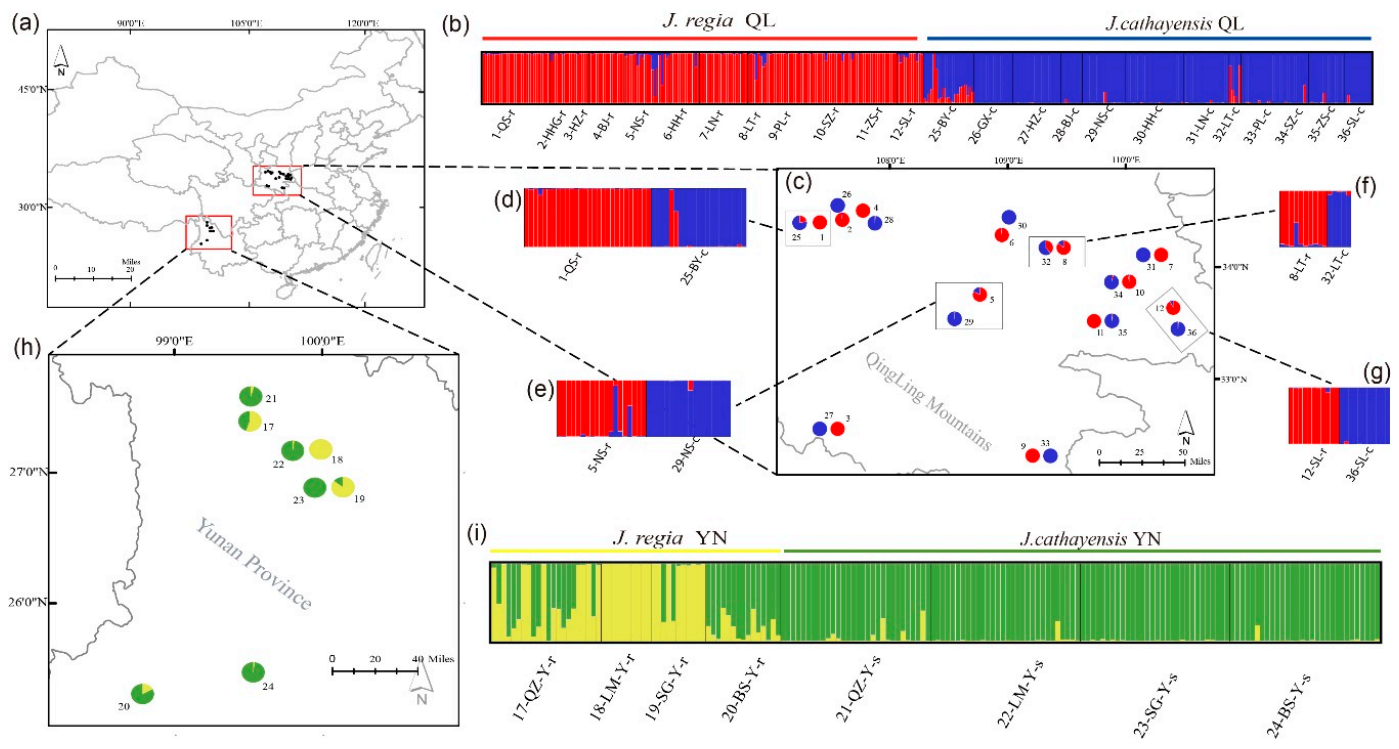

Figure 5. Genetic structure and geographical distribution of 32 sympatric walnut (Juglans) populations based on 17 EST-SSRs in the Qinling Mountains and Yunnan Province. (a) The map of sample collection information for the three walnuts (J. regia, J. cathayensis, and J. sigillata). (b) Results of the STRUCTURE 2.3.4 analysis showing $K=2$. A total of 24 sympatric J. regia versus J. cathayensis populations based on 17 EST-SSRs in the Qinling Mountains. (c) Geographic origin of the 12 pairs of sympatric J. regia versus $J$. cathayensis populations and their color-coded grouping at the most likely $K=2$, as determined using the deltaK method of Evanno et al. (2005) [62]. The location of the pie indicates the sampled locations. $(\mathbf{d}-\mathbf{g})$. Results of the four pairs of sympatric J. regia versus J. cathayensis populations (1-QL-r versus 25-BY-c; 5-NS-r versus 29-NS-c; 8-LT-r versus 32-LT-c; 12-SL-r versus 36-SL-c) of STRUCTURE 2.3.4 analysis, shown from $K=2$. (h) Genetic structure and geographical distribution of eight sympatric J. regia versus J. sigillata populations based on 17 EST-SSRs in Yunnan province. (i) Results of the sympatric J. regia versus J. sigillata populations from the Yunnan province via the STRUCTURE 2.3.4 analysis, shown from $K=2$. 
The genetic structures of the four pairs of J. regia and J. sigillata populations with sympatric distribution from Yunnan province were evaluated by Bayesian cluster analysis using STRUCTURE. The log-likelihood values reached three peaks when $K>2$, and the values of delta $K$ were highest when $K$ was 2 [55,62] (Figure S3c). At $K=2$, cluster I (west group) included four J. regia populations found in Yunnan province, and cluster II (east group) was comprised of four J. sigillata populations from Yunnan province (Figure 5h,i). Two populations (17-QZ-Y-r, 20-BS-Y-r) between the west and the east cluster were identified as admixed. Consistently, the number of subclusters for each larger $K$ was much lower than the number of sampled populations. The results of the STRUCTURE analysis inevitably indicate extensive gene flow, either historical or ongoing (Figure 5i).

\section{Discussion}

\subsection{Genetic Diversity and the Spatial Genetic Structure of J. regia, J. sigillata, and J. cathayensis}

Landscape genetics can be regarded as a self-explanatory tool, which can transmit information about the spatial distribution of genetic variation into practice [65]. However, few scholars have combined landscape genetics and genetic diversity studies to analyze the biogeographical history of a species $[65,66]$. Previous studies have suggested that $R s$ and $H_{E}$ are very useful indicators to measure genetic diversity and are considered ideal indicators to determine conservation priorities [67]. Here, we compare the spatial manifestations of $H e, R s$, and $P_{A R}$, so as to vividly infer the biogeographic history of walnut-related species in the two regions (Figures 2 and 3). Interestingly, the high $\mathrm{He}$ and $R s$ values of J. regia populations were observed in the eastern and western of Qinling Mountains, whereas the low values of $P_{A R}$ appeared in the same regions. This may be due to the fact that J. regia populations, as important nut trees in the eastern and western regions of the Qinling Mountains, experienced more frequent artificial disturbance, which increased genetic diversity in these areas and erased ancient signs of refugia. Unlike the J. cathayensis populations in Qinling Mountains, J. regia and the J. sigillata populations in Yunnan are an economic species, and domesticated species tend to become more scattered and exhibit relatively lower abundance due to human selection and human-mediated dispersal of selected genotypes, which also explains why the genetic diversity of $J$. cathayensis populations is higher than that of J. regia and J. sigillata populations. The same reason also explains the opposite distribution of the $R s$ and $P_{A R}$ values of $J$. regia populations in Yunnan.

This study is the first to explore the interspecific introgression of Chinese Juglans plants and provides a theoretical basis for the genetic evolution of the genus Juglans. In this study, we estimated the genetic diversity and genetic structure of 40 walnut populations sampled across its sympatric range using 17 microsatellite markers (nine neutral EST-SSRs and eight non-neutral EST-SSRs, Figure S2). For our analyses, eight of the seventeen loci were detected to be $F_{\mathrm{ST}}$ outliers: JC3412, JM5969, JC7329, JR4964, JR4616, JM78331, JR6160, and JR1817 (Figure S2). The microsatellite loci screened in this study may be located within functional genes. All loci were annotated using Pfam, the GO database, and blastx of NCBI [68]. EST-SSR stands for expressed sequence tags, in coding regions and potentially under selection $[43,68]$. The STRUCTURE results based on the neutral loci and selected loci were not significantly and consistently the same among the three Juglans species (Figure 3). The structure analysis of the two groups of Juglans based on the EST-SSR data indicated that J. regia and J. cathayensis have strong reproductive isolation and rarely exhibit gene introgression phenomena, while J. regia and J. sigillata have no obvious genetic boundaries and frequently exhibit gene introgression phenomena (Figures 4 and 5). These findings are consistent with those of of the UPGMA tree (Figure 4c), PCoA (Figure 4e), and the historical gene flow analysis (Table 3). Because of the limitation of pollen diffusion, we used the four pairs of sympatric J.regia versus J.cathayensis populations (1-QL-r versus 25-BY-c; 5-NS-r versus $29-N S-c$; 8-LT-r versus 32-LT-c; $12-$ SL-r versus $36-S L-c)$ with relatively more gene flow to carry out structure analysis (Figure $5 \mathrm{~d}-\mathrm{g}$ ). In summary, strong reproductive isolation and low-level gene introgression occurred between sympatric J. regia and J. cathayensis populations. Our study provides an additional study on the three species of Juglans to provide theoretical support for the 
genetic conservation of intergeneric plants. The experimental objects of this study are important economic tree species, which have experienced too much human interference. To further study the gene flow between plant genera, more forest tree species need to be studied.

\subsection{Species Classification of J. regia and J. sigillata}

A species in the center of its habitat may present some minor adaptive changes from time to time, but they are only varieties and retain a certain geographical distribution. Previous studies on the morphology, molecular biology, phenological, and fossils of Juglans have shown that there are five species of Juglans in China, which are classified into two groups: section Juglans and section Cardiocaryon. Section Juglans includes the two cultivated walnuts, J. regia and J. sigillata. However, there is a long-standing controversy about whether J. sigillata is a variety or an independent species. Although there are obvious morphological differences between J. regia and J. sigillata, many studies have indicated that these two species have no genetic barriers. Structural analysis and gene flow analysis based on four pairs of sympatric populations in Yunnan showed that J. regia and J. sigillata have obvious gene flow, and directional gene flow has been mainly from J. regia to J. sigillata. Combined with previous research results, we prefer to support the view that $J$. sigillata is a sub-species or, perhaps, a landrace of J. regia. Zhao et al. [29] and Yuan et al. [43] have also provided powerful evidence for the establishment of this hypothesis through other molecular techniques. However, some studies have shown that, although there is a high level of gene flow between oak (Quercus) and pine (Pinus) tree species [69-71], they both still maintain the integrity of their species, which also reflects the complex phenomenon of gene introgression and hybridization between species.

\subsection{Influencing Factors of Distinct Gene Introgression among Three Juglans Species}

Hybridization may have played an important role in the genetic differentiation of Juglans, and the phenomenon of interspecific hybridization has been strongly confirmed [36-43]. Accordingly, we selected two groups of walnut species to study. The two cultivated walnuts of section Juglans (J. regia and J. sigillata) were from Yunnan province, while J. regia of section Juglans and J. cathayensis of section Cardiocaryon were from the Qingling Mountains. It is noteworthy that the natural coexistence of J. regia and J. sigillata is very narrow. The results of the STRUCTURE analysis (Figures 4 and 5), the UPGMA tree (Figure 4c), $P C o A$ (Figure 4e), and the historical gene flow analysis (Table 3) indicate that gene introgression is common among the same groups of Juglans, as only rare and low-level gene introgression appears in distinct groups.

In plants, interspecific gene introgression often occurs due to the hybridization of closely-related species distributed in the same region. The analysis results of the genetic diversity and genetic structure of J. regia and J. sigillata showed that J. regia and J. sigillata have frequent gene flow, which might be due to the dispersal of pollen or seeds to achieve gene introgression among populations, further reducing the genetic divergence of different species. The persion walnut and the iron walnut, which are important economic tree species in China, have been seriously disturbed by human activities. This disturbance may also interfere with the two-way direction of gene introgression between the two closely-related species. However, compared with the frequent gene flow between two closely related species (J. regia and J. sigillata), the STRUCTURE results showed that there was a strong reproductive isolation mechanism between the distant species, J. regia and J. cathayensis, in different groups, and hybridization is a rare event. We speculated that the possible reasons for this rarity are related to the reproductive isolation mechanism. A reproductive isolation mechanism among some species is sufficient to maintain the integrity of the species, but relevant studies have shown that multiple isolation mechanisms need to work together among two related species, as an isolation mechanism can almost completely block the gene flow between the two species [72]. However, even if the probability of hybridization is very low, it is normal to occasionally find individual hybridization events. Natural hybridization and gene introgression are ubiquitous among and within genera of plants, thereby providing the main impetus for plant evolution. However, the overwhelming majority 
of species retain species stability, even at a high levels of gene flow. This also indicates that there may be complex mechanisms for maintaining stability among species, or, possibly, genes controlling species' divergence may not change due to gene flow among species, thereby maintaining the independence of the species.

\section{Conclusions}

In this study, 656 individuals from 40 Persian walnut, Chinese walnut, and iron walnut populations were genotyped with 17 EST-SSRs to analyze the gene introgression among J. regia and J. cathayensis, J. regia, and J. sigillata. In summary, J. regia and J. cathayensis showed strong reproductive isolation and rare gene introgression phenomena, and J. regia and J. sigillata had no obvious genetic boundaries and frequent gene introgression phenomena. For the three species of Juglans, all of the above results indicate that gene introgression is common among species in the same group of Juglans, and only rare and low-level gene introgression appears in distinct groups. Our study provides information on three species of Juglans to provide theoretical support for the genetic conservation of intergeneric plants. The experimental object of this study was to analyze important economic tree species which have experienced too much human interference. To further study the gene flow between plant genera, more forest tree species need to be studied.

Supplementary Materials: The following are available online at http:/www.mdpi.com/1999-4907/10/11/965/s1. Figure S1. Genetic clustering of all individuals of J. regia, J. cathayensis, and J. sigillata. (a) Population cluster analysis of three walnut species using STRUCTURE $(K=2)$ based on 17 EST-SSR datasets. (b) Population cluster analysis of three walnut species using STRUCTURE $(K=2)$ based on eight non-neutral EST-SSR datasets. (c) Population cluster analysis of three walnut species using STRUCTURE $(K=2)$ based on nine neutral EST-SSR datasets. Figure S2. Detection of loci under the selection from genome scans based on FST. Eight of seventeen loci were detected to be the $F_{\mathrm{ST}}$ outlier: JC3412, JM5969, JC7329, JR4964, JR4616, JM78331, JR6160, and JR1817. Figure S3. (a-d) According to the whole-range STRUCTURE analysis using three datasets (based on all three walnut species, only sympatric with all J. regia versus J. cathayensis populations, all J. regia versus J. sigillata populations, and J. regia versus J. cathayensis populations in the Qinling Mountains), the values of the log-likelihood of the data, loge $\operatorname{Pr}(\mathrm{K})$, increased progressively with an increase in $K$, but delta $K$ indicated that the optimal values for $K$ were all 2 . Table S1. Information of primers and the genetic Characteristics of 17 EST-SSR primers for the 40 walnut populations used in this study. Table S2. Percentage of variation explained by the first three axes using the principal coordinate analysis model approach. Table S3. Description of private alleles by 17 populations. Table S4. Test results of the null alleles in 17 loci.

Author Contributions: Conceptualization: P.Z. and M.D.; conceiving and designing the experiments: P.Z. and M.D.; data curation: P.Z., M.Y., and M.D.; analyzing the data: P.Z., M.D., M.Y., M.Z., and G.Z.; funding acquisition: P.Z.; project administration: P.Z.; contributed materials/analysis tools: P.Z., M.D., M.Y., and G.Z.; writing-original draft preparation: P.Z. and M.D.; writing—review and editing: P.Z., M.D., M.Y., M.Z., and G.Z.

Funding: This work was supported by the National Natural Science Foundation of China $(41471038 ; 31200500)$, the Program for Excellent Young Academic Backbones funding by Northwest University, Shaanxi Academy of Science Research Funding Project (Y19Z604F12), Natural Science Foundation of Shaanxi Province of China (2019JM-008), and the public health specialty in the department of traditional Chinese Medicine (2017-66, 2018-43, 2019-68).

Conflicts of Interest: The authors declare no conflict of interest.

\section{References}

1. Neafsey, D.E.; Lawniczak, M.K.; Park, D.J.; Redmond, S.N.; Coulibaly, M.B.; Traore, S.F.; Sagnon, N.; Costantini, C.; Johnson, C.; Wiegand, R.C.; et al. SNP genotyping defines complex gene-flow boundaries among African malaria vector mosquitoes. Science 2010, 330, 514-517. [CrossRef] [PubMed]

2. Teeter, K.C.; Thibodeau, L.M.; Gompert, Z.; Buerkle, C.A.; Nachman, M.W.; Tucker, P.K. The variable genomic architecture of isolation between hybridizing species of house mice. Evolution 2010, 64, 472-485. [CrossRef] [PubMed]

3. Duvaux, L.; Belkhir, K.; Boulesteix, M.; Boursot, P. Isolation and gene flow: Inferring the speciation history of European house mice. Mol. Ecol. 2011, 20, 5248-5264. [CrossRef] [PubMed]

4. Qi, Y.; Lu, B.; Gao, H.Y.; Hu, P.; Fu, J.Z. Hybridization and mitochondrial genome introgression between Rana chensinensis and R. kukunoris. Mol. Ecol. 2014, 23, 5575-5582. [CrossRef] [PubMed] 
5. Slatkin, M. Gene flow and the geographic structure of natural populations. Science 1987, 236, 787-792. [CrossRef]

6. Xu, Y.; Zhang, M.Y.; Gao, L. The research of interspecific hybridization in genus Juglans. Decidous Fruits 2007, 32, 6-8.

7. Barton, N.H.; Gale, K.S. Genetic analysis of hybrid zones. In Hybrid Zones and the Evolutionary Process; Harrison, R.G., Ed.; Oxford University Press: New York, NY, USA, 1993; pp. 13-45.

8. Thompson, S.L.; Lamothe, M.; Meirmans, P.G.; Périnet, P.; Isabel, N. Repeated unidirectional introgression towards Populus balsamifera in contact zones of exotic and native poplars. Mol. Ecol. 2010, 19, 132-145. [CrossRef]

9. Lexer, C.; Fay, M.F.; Joseph, J.A.; Nica, M.; Heinze, B. Barrier to gene flow between two ecologically divergent populus species, $P$. alba (white poplar) and P. tremula (European aspen): The role of ecology and life history in gene introgression. Mol. Ecol. 2005, 14, 1045-1057. [CrossRef]

10. Van Loo, M.; Joseph, J.A.; Heinze, B.; Fay, M.F.; Lexer, C. Clonality and spatial genetic structure in Populus $\times$ canescens and its sympatric backcross parent $P$. alba in a central European hybrid zone. New Phytol. 2008, 177, 506-516. [CrossRef]

11. Floate, K. Extent and patterns of hybridization among the three species of Populus that constitute the riparian forest of southern Alberta. Can. J. Bot. 2004, 82, 253-264. [CrossRef]

12. Jiang, D.; Feng, J.J.; Dong, M.; Wu, G.; Mao, K.; Liu, J.Q. Genetic origin and composition of a natural hybrid poplar Populus $\times$ jrtyschensis from two distantly related species. BMC Plant Biol. 2016, 16, 89. [CrossRef] [PubMed]

13. Qiang, F.; Chen, S.F.; Li, M.W.; Guo, W.; Jing, H.J.; Wu, W.; Zhou, R.C.; Liao, W.B. Molecular evidence for natural hybridization between wild loquat (Eriobotrya japonica) and its relative E. prinoides. BMC Plant Biol. 2014, 14, 275.

14. Lu, A.M. The geographical dispersal of Juglandaceae. Acta Phytotaxon 1982, 20, 257-271.

15. Lu, A.M.; Stone, D.E.; Grauke, L.J. Juglandaceae. In Flora of China; Wu, Z.Y., Raven, P.H., Eds.; Science Press: Beijing, China, 1999; pp. 277-285.

16. APG III. An update of the Angiosperm Phylogeny Group classification for the orders and families of flowering plants: APG III. Bot. J. Linn. Soc. 2009, 161, 105-121. [CrossRef]

17. Pei, D.; Lu, X.Z. Walnut Germplasm Resources in China; China Forestry Publishing House: Beijing, China, 2011; pp. 1-208. (In Chinese)

18. Suo, Z.L.; Pei, D.; Ma, Q.G.; Jin, X.B. Genetic formation of paradox hybrids (Juglans) revealed by nrDNA IGS8-ETS1 region. AASRI Procedia. 2012, 1, 156-165. [CrossRef]

19. APG IV. An update of the Angiosperm Phylogeny Group classification for the orders and families of flowering plants: APG IV. Bot. J. Linn. Soc. 2016, 181, 1-20. [CrossRef]

20. Gunn, B.F.; Aradhya, M.; Salick, J.M.; Miller, A.J.; Yongping, Y.; Lin, L.; Xian, H. Genetic variation in walnuts (Juglans regia and J. sigillata; Juglandaceae): Species distinctions, human impacts, and the conservation of agrobiodiversity in Yunnan, China. Am. J. Bot. 2010, 97, 660-671. [CrossRef]

21. Hoban, S.; McCleary, T.; Schlarbaum, S.; Romero-Severson, J. Geographically extensive hybridization between the forest trees American butternut and Japanese walnut. Biol. Lett. 2009, 5, 324-327. [CrossRef]

22. Ross-Davis, A.; Huang, Z.; Mckenna, J.; Ostry, M.; Woeste, K. Morphological and molecular methods to identify butternut (Juglans cinerea) and butternut hybrids: Relevance to butternut conservation. Tree Physiol. 2008, 28, 1127-1133. [CrossRef]

23. Wang, H.; Pan, G.; Ma, Q.G.; Zhang, J.P.; Pei, D. The genetic diversity and introgression of Juglans regia and Juglans sigillata in Tibet as revealed by SSR markers. Tree Genet. Genomes 2015, 11, 804. [CrossRef]

24. Zhao, P.; Woeste, K. DNA markers identify hybrids between butternut (Juglans cinerea L.) and Japanese walnut (Juglans ailantifolia Carr.). Tree Genet. Genomes 2011, 7, 511-533. [CrossRef]

25. Dode, L.A. Contribution to the study of the genus Juglans. Bull. Soc. Dendrol. Fr. 1909, 11, $22-90$.

26. Manning, W.E. The classification within the Juglandaceae. Ann. Mo. Bot. Gard. 1978, 65, 1058-1087. [CrossRef]

27. Bai, W.N.; Wang, W.T.; Zhang, D.Y. Contrasts between the phylogeographic patterns of chloroplast and nuclear DNA highlight a role for pollen-mediated gene flow in preventing population divergence in an east Asian temperate tree. Mol. Phylogenet. Evol. 2014, 81, 37-48. [CrossRef] 
28. Dong, W.P.; Xu, C.; Li, W.Q.; Xie, X.M.; Lu, Y.Z.; Liu, Y.L.; Jin, X.B.; Suo, Z.L. Phylogenetic Resolution in Juglans Based on Complete Chloroplast Genomes and Nuclear DNA Sequences. Front. Plant Sci. 2017, 8, 1148. [CrossRef]

29. Zhao, P.; Zhou, H.J.; Potter, D.; Hu, Y.H.; Feng, X.J.; Dang, M. Population genetics, phylogenomics and hybrid speciation of Juglans in China determined from whole chloroplast genomes, transcriptomes, and genotypingby-sequencing (GBS). Mol. Phylogenet. Evol. 2018, 126, 250-265. [CrossRef]

30. Bai, W.N.; Wang, W.T.; Zhang, D.Y. Phylogeographic breaks within Asian butternuts indicate the existence of a phytogeographic divide in East Asia. New Phytol. 2015, 206, 1757-1772. [CrossRef]

31. Wang, H.; Pei, D.; Gu, R.S.; Wang, B.Q. Genetic diversity and structure of walnut populations in central and southwestern China revealed by microsatellite markers. J. Am. Soc. Hortic. Sci. 2008, 133, 197-203. [CrossRef]

32. Chen, L.; Ma, Q.; Chen, Y.; Wang, B.; Pei, D. Identification of major walnut cultivars grown in China based on nut phenotypes and SSR markers. Sci. Hortic. 2014, 168, 240-248. [CrossRef]

33. Guo, Y.X.; Li, G.; Hu, Y.N.; Kang, D.; Wang, D.X.; Yang, G.H. Regeneration of Betula albosinensis in strip clearcut and uncut forests of the Qinling Mountains in China. PLoS ONE 2013, 8, e59375. [CrossRef]

34. Pollegioni, P.; Woeste, K.; Mugnozza, G.S.; Malvolti, M.E. Retrospective identification of Hybridogenic walnut plants by SSR fingerprinting and parentage analysis. Mol. Breed. 2009, 24, 321. [CrossRef]

35. Bai, W.N.; Liao, W.J.; Zhang, D.Y. Nuclear and chloroplast DNA phylogeography reveal two refuge areas with asymmetrical gene flow in a temperate walnut tree from East Asia. New Phytol. 2010, 188, 892-901. [CrossRef] [PubMed]

36. Zhao, P.; Zhou, H.J.; Liu, Z.L.; Woeste, K.; Hu, D.F.; Dang, M.; Li, Z.H.; Wang, M.L.; Zhao, G.F. A review of research progress on molecular phylogeny and biogeography in Juglans. Sci. Silvae Sin. 2014, 50, 147-157. (In Chinese)

37. Dang, M.; Zhang, T.; Hu, Y.H.; Zhou, H.J.; Woeste, K.; Zhao, P. De Novo Assembly and Characterization of Bud, Leaf and Flowers Transcriptome from Juglans regia L. for the Identification and Characterization of New EST-SSRs. Forests 2016, 7, 247. [CrossRef]

38. Dang, M.; Liu, Z.X.; Chen, X.; Zhang, T.; Zhou, H.J.; Hu, Y.H.; Zhao, P. Identification, development, and application of 12 polymorphic EST-SSR markers for an endemic Chinese walnut (Juglans cathayensis D.) using next-generation sequencing technology. Biochem. Syst. Ecol. 2015, 60, 74-80. [CrossRef]

39. Han, H.; Woeste, K.; Hu, Y.H.; Dang, M.; Zhang, T.; Gao, X.X. Genetic diversity and population structure of common walnut (Juglans regia) in China based on EST-SSRs and the nuclear gene phenylalanine ammonia-lyase (PAL). Tree Genet. Genomes 2016, 12, 111. [CrossRef]

40. Hu, Y.H.; Zhao, P.; Zhang, Q.; Wang, Y.; Gao, X.X.; Zhang, T. De novo assembly and characterization of transcriptome using Illumina sequencing and development of twenty five microsatellite markers for an endemic tree Juglans hopeiensis Hu in China. Biochem. Syst. Ecol. 2015, 63, 201-211. [CrossRef]

41. Hu, Z.; Zhang, T.; Gao, X.X.; Wang, Y.; Zhang, Q.; Zhou, H.J. De novo assembly and characterization of the leaf, bud, and fruit transcriptome from the vulnerable tree Juglans mandshurica for the development of 20 new microsatellite markers using Illumina sequencing. Mol. Genet. Genom. 2015, 291, 849-862. [CrossRef]

42. Shu, Z.; Zhang, X.; Yu, D.Q.; Xue, S.J.; Wang, H. Natural Hybridization between Persian Walnut and Chinese Walnut Revealed by Simple Sequence Repeat Markers. J. Am. Soc. Hortic. Sci. 2016, 141, 146-150. [CrossRef]

43. Yuan, X.Y.; Sun, Y.W.; Bai, X.R.; Dang, M.; Feng, X.J.; Saman, Z.; Zhao, P. Population Structure, Genetic Diversity, and Gene Introgression of Two Closely Related Walnuts (Juglans regia and J. sigillata) in Southwestern China Revealed by EST-SSR Markers. Forests 2018, 9, 646. [CrossRef]

44. Doyle, J.J.; Doyle, J.L. A rapid DNA isolation procedure for small quantities of fresh leaf tissue. Phytochem. Bull. 1987, 19, 11-15.

45. Peakall, R.; Smouse, P.E. GenAlEx 6.5: Genetic analysis in ExceL. Population genetic software for teaching and research-an update. Bioinformatics 2012, 28, 2537-2539. [CrossRef] [PubMed]

46. Kalinowski, S.T. HP-Rare: A computer program for performing rarefaction on measures of allelic diversity. Mol. Ecol. Notes 2005, 5, 187-189. [CrossRef]

47. Van Oosterhout, C.; Hutchinson, W.F.; Wills, D.P.; Shipley, P. MICRO-CHECKER: Software for identifying and correcting genotyping errors in microsatellite data. Mol. Ecol. Resour. 2004, 4, 535-538. [CrossRef] 
48. Tsuda, Y.; Nakao, K.; Ide, Y.; Tsumura, Y. The population demography of Betula maximowicziana, a cool-temperate tree species in Japan, in relation to the last glacial period: Its admixture-like genetic structure is the result of simple population splitting not admixing. Mol. Ecol. 2015, 24, 1403-1418. [CrossRef]

49. Luikart, G.; England, P.R.; Tallmon, D.; Jordan, S.; Taberlet, P. The power and promise of population genomics: From genotyping to genome typing. Nat. Rev. Genet. 2003, 4, 981-994. [CrossRef]

50. Antao, T.; Lopes, A.; Lopes, R.J.; Beja-Pereira, A.; Luikart, G. LOSITAN: A workbench to detect molecular adaptation based on a FST-outlier method. BMC Bioinform. 2008, 9, 323. [CrossRef]

51. Rousset, F. Genepop'007: A complete re-implementation of the genepop software for windows and Linux. Mol. Ecol. Resour. 2008, 8, 103-106. [CrossRef]

52. Goudet, J. FSTAT (Version 2.9.3.): A Program to Estimate and Test Gene Diversities and Fixation Indices. Available online: http://www2.unil.ch/popgen/softwares/fstat.htm (accessed on 2 February 2002).

53. Kalinowski, S.T.; Taper, M.L.; Marshall, T.C. Revising how the computer program CERVUS accommodates genotyping error increases success in paternity assignment. Mol. Ecol. 2007, 16, 1099-1106. [CrossRef]

54. Excoffier, L.; Lischer, H.E. Arlequin suite ver 3.5: A new series of programs to perform population genetics analyses under Linux and Windows. Mol. Ecol. Resour. 2010, 10, 564-567. [CrossRef]

55. Pritchard, J.K.; Stephens, M.; Donnelly, P. Inference of population structure using multilocus genotype data. Genetics 2000, 155, 945-959. [PubMed]

56. Earl, D.A.; von Holdt, B.M. STRUCTURE HARVESTER: A website and program for visualizing STRUCTURE output and implementing the Evanno method. Conserv. Genet. Resour. 2012, 4, 359-361. [CrossRef]

57. Rosenberg, N.A. DISTRUCT: A program for the graphical display of population structure. Mol. Ecol. Resour. 2004, 4, 137-138. [CrossRef]

58. Nei, M. Analysis of gene diversity in subdivided populations. Proc. Natl. Acad. Sci. USA 1973, 70, 3321-3323. [CrossRef] [PubMed]

59. Takezaki, N.; Nei, M.; Tamura, K. POPTREE2: Software for constructing population trees from allele frequency data and computing other population statistics with windows interface. Mol. Ecol. Resour. 2010, 27, 747-752. [CrossRef] [PubMed]

60. Rambaut, A. FigTree, Version 1.3.1. Computer Program Distributed by the Author. Available online: http://tree.bio.eD.ac.uk/software/figtree/ (accessed on 4 January 2011).

61. Beerli, P. Comparison of Bayesian and maximum-likelihood inference of population genetic parameters. Bioinformatics 2005, 22, 341-345. [CrossRef] [PubMed]

62. Evanno, G.; Regnaut, S.; Goudet, J. Detecting the number of clusters of individuals using the software STRUCTURE: A simulation study. Mol. Ecol. 2005, 14, 2611-2620. [CrossRef]

63. El-Kassaby, Y.A.; Thomson, A.J. Parental rank changes associated with seed biology and nursery practices in Douglas-fir. For. Sci. 1996, 42, 228-235.

64. Michael, U.S.; Yousry, A.E. Challenges Facing the Forest Industry in Relation to Seed Dormancy and Seed Quality. BMC Plant Biol. 2011, 773, 3-15.

65. Claudia, M.M.; Angela, M.; Francesca, C.; Marcello, C.; Muriel, G.; Paola, P.; Ivaylo, V.; Rob, J.; Frank, M.; Chambers, L.P.; et al. Landscape genetics structure of European sweet chestnut (Castanea sativa Mill): Indications for conservation priorities. Tree Genet. Genomes 2017, 13, 39.

66. Bowman, J.; Greenhorn, J.E.; Marrotte, R.R.; McKay, M.M.; Morris, K.Y.; Mrentice, M.B.; Wehtje, M. On application of landscape genetics. Conserv. Genet. 2016, 17, 753-760. [CrossRef]

67. Van Zonneveld, M.; Scheldeman, X.; Escribano, P. Mapping genetic diversity of cherimoya (Annona cherimola mill.): Application of spatial analysis for conservation and use of plant genetic resources. PLoS ONE 2012, 7, e29845. [CrossRef] [PubMed]

68. Feng, X.J.; Zhou, H.J.; Zulfiqar, S.; Luo, X.; Hu, Y.H.; Feng, L.; Malvolti, M.; Woeste, K.; Zhao, P. The Phytogeographic History of Common Walnut in China. Front. Plant Sci. 2018, 9, 1399. [CrossRef] [PubMed]

69. Fortini, P.; Di Marzio, P.; Di Pietro, R. Differentiation and hybridization of Quercus frainetto, Q. petraea, and Q. pubescens (Fagaceae): Insights from macro-morphological leaf traits and molecular data. Plant Syst. Evol. 2015, 301, 375-385. [CrossRef]

70. Whittemore, A.T.; Schaal, B.A. Interspecific gene flow in sympatric oaks. Proc. Natl. Acad. Sci. USA 1991, 88, 2540-2544. [CrossRef] 
71. Zhou, Y.F.; Abbott, R.J.; Jiang, Z.Y.; Du, F.K.; Milne, R.I.; Liu, J.Q. Gene flow and species delimitation: A case study of two species with overlapping distributions in southeast China. Evolution 2010, 64, 2342-2352.

72. Lowry, D.B.; Modliszewski, J.L.; Wright, K.M. The strength and genetic basis of reproductive isolating barriers in flowering plants. Philos. Trans. R. Soc. B Biol. Sci. 2008, 363, 3009-3021. [CrossRef]

(C) 2019 by the authors. Licensee MDPI, Basel, Switzerland. This article is an open access article distributed under the terms and conditions of the Creative Commons Attribution (CC BY) license (http://creativecommons.org/licenses/by/4.0/). 